\title{
Entre o "gostar" de estar na escola e a invisibilidade juvenil: um estudo sobre jovens estudantes de Santa Maria, RS
}

\author{
Elisete Medianeira Tomazetti* \\ Nara Vieira Ramos** \\ Sueli Salva*** \\ Adriano Machado Oliveira**** \\ Vitor Schlickmann ${ }^{* \star * \star *}$
}

\begin{abstract}
Resumo
Este artigo coloca em pauta os jovens estudantes de Ensino Médio da cidade de Santa Maria e algumas de suas perspectivas relacionadas ao processo de escolarização. Santa Maria, pela sua condição de cidade universitária, interfere significativamente na vida escolar dos jovens. Tomamos como referência para esse texto a pesquisa "Educação e Juventude: jovens das escolas públicas de Ensino Médio de Santa Maria", realizada ao longo do ano de 2009, cujos dados são resultantes de entrevistas com 370 jovens do Ensino Médio, envolvendo escolas situadas na zona urbana e rural de Santa Maria. A metodologia definida pela investigação constitui-se de duas etapas, uma quantitativa, em que os dados foram levantados e analisados, e outra qualitativa, a que utiliza como método "grupos de diálogo", técnica utilizada em outras investigações com jovens e que privilegia o diálogo e a expressão juvenil. O texto apresenta, inicialmente, uma discussão ampla acerca da juventude e dos processos de escolarização e, posteriormente, os dados e as análises correspondentes à referida pesquisa. Por fim, focalizamos e debatemos dois pontos: o "gostar" de estar na escola na perspectiva dos jovens e a invisibilidade da cultura desse segmento social no âmbito escolar.
\end{abstract}

Palavras-chave: Jovens; Ensino Médio; Invisibilidade juvenil.

\footnotetext{
* Professora Doutora do Programa de Pós-Graduação em Educação, Centro de Educação, Universidade Federal de Santa Maria, Santa Maria, Rio Grande do Sul, Brasil.

** Professora Doutora do Programa de Pós-Graduação em Educação, Centro de Educação, Universidade Federal de Santa Maria, Santa Maria, Rio Grande do Sul, Brasil.

*** Professora Doutora do Programa de Pós-Graduação em Educação, Centro de Educação, Universidade Federal de Santa Maria, Santa Maria, Rio Grande do Sul, Brasil.

**** Professor da Universidade Federal do Tocantins(UFT) - Doutorando do Programa de PósGraduação em Educação da Universidade Federal de Santa Maria (UFSM).

***** Professor da Faculdade da Serra Gaúcha, Caxias do Sul (FSG) e do Programa de PósGraduação em Educação, Centro de Educação, Universidade Federal de Santa Maria, Santa Maria, Rio Grande do Sul, Brasil.
} 
Elisete M. Tomazetti - Nara V. Ramos - Sueli Salva -

Adriano M. Oliveira - Vitor Schlickmann

\title{
Between "enjoying" being at school and juvenile invisibility: a study of
} young students from Santa Maria, RS

\begin{abstract}
This article deals with high school students from Santa Maria and some of their perspectives concerning the schooling process. Santa Maria, as a university city, interferes significantly in the school life of young people. We take as reference for this article the research project "Educação e Juventude: jovens das escolas públicas de Ensino Médio de Santa Maria" [Education and Youth: young people from public secondary schools in Santa Maria], carried out in 2009, whose data are derived from interviews with 370 young high school students, involving schools in urban and rural areas of Santa Maria. The methodology of the research consisted of two stages, a quantitative one, in which data were collected and analyzed, and a qualitative one, which used "dialogue groups" as a method, a technique used in other investigations with teenagers that favors dialogue and juvenile expression. At first the text presents a broad discussion about teenagers and schooling processes; further, some data and analysis relevant for this search. Finally, we focus on and discuss two points: the "enjoying" being at school from the perspective of youth culture and the invisibility of this social segment in the school.
\end{abstract}

Keywords: Teenagers; High school; Juvenile invisibility.

\section{Juventude e processos de escolarização}

A construção da ideia de juventude foi influenciada pelo processo de escolarização. A preocupação com a formação das novas gerações permitiu que parte da população jovem se constituísse como grupo com características próprias. A escolarização afastou os jovens do convívio com as crianças e gerações mais velhas, contribuindo para a construção de um espaço para uma educação específica. Constata-se também que, inicialmente, um grupo muito restrito teve direito de frequentar a escola, estruturada de modo a atender às necessidades desse grupo. Nas últimas décadas do século $X X$, houve um intenso processo de ampliação do ensino, com o objetivo de estender o atendimento a outros grupos da população, como forma de suprir as demandas de uma sociedade em processo de expansão.

De acordo com Sposito (2005, p. 89), a condição juvenil na sociedade ocidental moderna foi caracterizada pela manutenção de relações importantes com duas instituições: a família e a escola. Esta, considerada um espaço formativo, pode ser analisada a partir do conceito de modo de reprodução, conforme Bourdieu (1992, p. 20): "Toda ação pedagógica é objetivamente uma violência simbólica enquanto imposição, por um poder arbitrário, de um arbitrário cultural". Tal ação faz com que sejam interiorizadas percepções, valores e sen- 
Entre o "gostar" de estar na escola e a invisibilidade juvenil: um estudo sobre jovens estudantes de Santa Maria, RS

timentos por crianças e jovens que, para Criado (2004, p. 75), "logo serão capazes de reproduzi-los em suas práticas, gostos e escolhas".

Entretanto, à medida que foi se expandindo, a escola tornou-se um espaço de "intensificação e abertura das interações com o outro e, portanto, caminho privilegiado para a ampliação da experiência de vida dos jovens" (SPOSITO, 2005, p. 90). Esse processo permitiu que se construísse um ambiente de acolhimento a novas dinâmicas, e, da parte dos professores, exigiu melhor preparação e contínua atualização. A crise da escola, no entanto, não está restrita ao Ensino Médio, mas à instituição escolar de uma forma geral: "sua dimensão socializadora baseia-se mais na capacidade do próprio aluno de criar mecanismos para se movimentar no sistema do que numa ação pedagógica dirigida à interiorização de hábitos, valores, modelos de conduta e princípios, quaisquer que sejam eles" (SOUZA, 2003, p. 43).

Diante desse quadro, como poderíamos compreender as relações que os jovens estabelecem com a escola de Ensino Médio? Para Fanfani (2000), no leque possível de respostas, encontram-se: 1) A obrigação como sentido: não há outro jeito, o Ensino Médio é necessário; 2) A razão instrumental: deve-se estudar por uma razão puramente instrumental, é preciso esforçar-se nos estudos para ser "alguém na vida" no futuro; e 3) O amor ao conhecimento: paixão pelo conhecimento, energia poderosa para o êxito na carreira escolar.

Socialmente, a última resposta talvez seja a mais referida por aqueles jovens oriundos de classes onde inexiste a preocupação com problemas relativos à sobrevivência. Em contrapartida, aos jovens excluídos ou que cotidianamente devem garantir as condições de subsistência, restam as duas primeiras possíveis respostas, principalmente a segunda. Contudo, diante das dificuldades do dia a dia, o sacrifício por e pela escolarização perde o sentido que deveria assumir, tornando-se "algo absurdo e literalmente impensável" (FANFANI, 2000, p. 12-13).

Mesmo que a escolarização no nível médio configure-se, em tempos atuais, como sendo de expansão e de acesso quase que universal, há outras metas a serem atingidas - por exemplo, a permanência dos jovens na escola e o ensino de qualidade. A dificuldade em atingi-las é fruto de vários fatores e não é exclusividade das escolas de nosso país: a maioria dos jovens chilenos aponta como principal motivo de abandono escolar o "desinteresse e falta de motivação para o estudo" (PEREZ apud DAYRELL, 2003, p. 173).

Dessa maneira, a compreensão do desinteresse e da desmotivação coloca a exigência de análise da cultura escolar contemporânea e, detalhadamente, das formas como as culturas juvenis são reconhecidas e incluídas no e pelo projeto das escolas. São recorrentes afirmações acerca de como a cultura escolar, ao longo do tempo, cristalizou valores, discursos e normas expressadas em seus currículos, cujas práticas foram pautadas na 
Elisete M. Tomazetti - Nara V. Ramos - Sueli Salva -

Adriano M. Oliveira - Vitor Schlickmann

homogeneidade, sistematização, continuidade, coerência, ordem e, consequentemente, não-abertura de espaço para as culturas do novo de que jovens alunos são portadores. Constatar isso, todavia, não é suficiente. Em outras palavras, faz-se necessário pensar em um ensino capaz de incorporar a vida dos jovens nas práticas escolares e, assim, amenizar situações como a desmotivação.

Para superar esse modelo sedimentado, talvez seja necessário que a escola incentive a inclusão e a participação dos jovens em seus projetos, ao mesmo tempo em que o diálogo e a reflexão sejam objetos de ensino e de aprendizagem, pois o "conhecimento escolar deveria refletir as demandas dos jovens, com programas de estudo que os vinculem às suas comunidades e à realidade em que vivem". A escola deveria, portanto, tornar-se um "centro juvenil", sustentado por uma "pedagogia da juventude" (PEREZ apud DAYRELL, 2003 p. 178).

A expansão quantitativa realizada pelo poder público, a qual parecia ser a solução de muitos problemas relacionados à educação, quando feita de maneira isolada, encaminha para um equívoco. É preciso que o Estado invista igualmente em recursos com vistas à implementação e qualificação da escola, tanto em infraestrutura material quanto em formação de professores, que necessitam de preparação específica para se relacionar com jovens e para lograr desenvolver uma pedagogia capaz de atender a essa especificidade.

Para Corea (2008, p. 42), encontramo-nos em um período sócio-histórico em que os professores não conseguem mais exercer sobre os jovens o mesmo poder subjetivador, pelo qual esses profissionais definiam sua autoridade e papel na instituição escolar e na sociedade. Não somente se encontram distanciados em relação aos códigos linguísticos que seus alunos possuem, como, de igual maneira, não conseguem elaborar operações que permitam construir sentidos junto aos jovens. Em outras palavras, o poder de instituir da escola já não existe; o que há, de fato, é uma destituição da escola de sua posição de agente subjetivador hegemônico sobre a população juvenil, tal como se dava até meados do século XX. Desse modo, no lugar de uma autoridade docente construída sobre códigos compartilhados no espaço escolar, verifica-se a ausência de sentido dessa instituição para muitos alunos e o fracasso na sala de aula como dispositivo formador perante a sociedade.

Tal situação de esgotamento da capacidade instituinte das escolas nos remete inevitavelmente às formas como os sujeitos contemporâneos têm promovido seus processos de subjetivação. Para Bauman (1998, 2009), a cultura pós-moderna inaugura uma proliferação de formas de ser que destitui os antigos critérios valorativos de sociabilidade. Religião, ideologia, etnia, classe social já não são critérios para as políticas de vida de nossos dias. Para esse autor, isso se deve à progressiva singularização dos itinerários existenciais, ao longo do século $X X$, os quais são sustentados pelas retóricas do mercado. Isso 
Entre o "gostar" de estar na escola e a invisibilidade juvenil: um estudo sobre jovens estudantes de Santa Maria, RS

significa que a antiga preocupação com o outro, com a comunidade e com a política estão num segundo plano diante das incessantes buscas pessoais orientadas pelo jogo consumista. No entanto, os critérios de valoração elaborados pela publicidade na busca de compradores são voláteis, de duração incerta, sendo suas premissas comportamentais, esboçadas nas propagandas dos mais variados produtos, completamente alheias às noções de coletividade e comunidade. Desse modo, o território antes sólido das sociedades modernas agora dá lugar à instantaneidade e incerteza como atributos do mundo, sem que homens e mulheres consigam satisfatoriamente encontrar lugares estáveis para ancorarem a construção de suas identidades pessoais (COSTA, 2005; BAUMAN, 1998).

Dentre esses lugares, a instituição escolar já não consegue oferecer suas narrativas como elementos de construção do eu para jovens e adolescentes e tampouco ofertar-lhes recursos para enfrentarem a fluidez do cenário em que vivem. Para Corea (2008, p. 45), tal situação de ineficácia das narrativas escolares tem um de seus fatores, igualmente, na velocidade das informações e do fluxo comunicacional do mundo digital.

\section{Juventude e Ensino Médio: um estudo na cidade de Santa Maria}

Os dados quantitativos de nossa investigação referem-se a 370 jovens, distribuídos em 13 escolas públicas do município de Santa Maria. Desses, $45,68 \%$ estão no primeiro ano, $31,89 \%$ estão no segundo e $19,19 \%$, no terceiro ano. Em Santa Maria, havia 20 escolas de Ensino Médio (no período pesquisado), localizadas na zona urbana e 01 na zona rural do município. A pesquisa foi realizada por amostragem probabilística, proporcional ao tamanho da amostra, onde a medida de tamanho foi o número de jovens entre 15 e 24 anos matriculados em 2006. A partir desse total, foi realizado um cálculo percentual por escola, definindo o número de alunos e alunas por turno e por ano do Ensino Médio a serem entrevistados. Para se estabelecer o número de jovens entrevistados nas escolas, consideraram-se os dados estatísticos da Pesquisa Nacional por Amostragem de Domicílios - PNAD/IBGE, ano 2003, que evidencia que há na cidade de Santa Maria um número mais elevado de jovens do sexo feminino no Ensino Médio. Desse modo, em todas as escolas foram entrevistadas mais jovens mulheres, totalizando $54,86 \%$. Esse dado estatístico nos levou a refletir sobre um fenômeno bem contemporâneo, que se refere à superioridade das mulheres, em anos de escolarização, em comparação com os homens (CORTI; SOUZA, 2004).

Historicamente, as mulheres tiveram acesso à escolarização depois dos homens, e também eram diferentes os conteúdos recebidos por elas nas escolas, que enfatizavam mais a instrução do que a educação. Com as políticas de expansão do ensino implementadas no Brasil a partir da década de 60 e as conquistas do movimento feminista, ocorreram mudanças significativas em relação ao acesso das mulheres à educação. Os dados do Censo Escolar de 2003 mostram que a matrícula inicial de crianças do sexo feminino era de $48,6 \%$ do 
Elisete M. Tomazetti - Nara V. Ramos - Sueli Salva -

Adriano M. Oliveira - Vitor Schlickmann

total de matrículas, mas, à medida que a escolarização avança, as mulheres passam a ser a maioria em 5.395 municípios brasileiros que ofertam o Ensino Médio, dado que se confirma também na cidade de Santa Maria. De acordo com Corti; Souza (2004), a presença feminina nas escolas é influenciada pelo ingresso das mulheres no mercado de trabalho, o que as força a buscar melhores níveis de escolaridade na tentativa de superar a discriminação salarial.

Ao analisar os dados referentes à inserção dos jovens no mercado de trabalho, percebemos que há um percentual de $22,43 \%$ de jovens já inseridos. Esse dado indica que muitos jovens trabalham no turno inverso ao das aulas, o que demonstra que, mesmo com as mudanças que estão ocorrendo no mundo atual, o trabalho continua sendo um valor ou referência importante em nossa sociedade. As motivações são as seguintes: "a) O trabalho é essencial à sobrevivência e ao consumo [...]; b) é também um espaço de socialização, de aprendizagem e construção de identidade pessoal e grupal, em suma, uma referência básica de inclusão social" (LEITE, 2003, p. 156).

Reconhecendo que os jovens são atores sociais e possuem novas identidades coletivas, faz-se necessário repensar o trabalho sob novos paradigmas. Já não se trata de "trabalho como atenuante da pobreza ou alternativa à marginalidade e à exclusão", mas sim "como direito e um componente essencial de formação do jovem, como indivíduo e cidadão" (LEITE, 2003, p. 157). Entretanto, aqui constatamos problemas, porque, ao mesmo tempo em que ocorre esse reconhecimento, também se impõe a realidade de mercado, visto que, à medida que ocorrem mudanças tecnológicas, organizacionais e políticas, essas vêm acompanhadas da redução da oferta de empregos e do aumento de exigências para o ingresso no mundo do trabalho. As empresas tornam-se mais exigentes e também aumenta a dificuldade em comprovar experiência.

No que se refere às atividades oferecidas pela escola que se diferenciem do padrão das aulas tradicionais, as atividades que mais se destacam são debates, excursões, filmes e visitas a museus. Entretanto, um percentual de $94,32 \%$ de jovens indica que sua escola não oferta atividades dessa natureza.

Em relação ao grêmio estudantil, percebemos que há pouca participação, apontada por apenas $9,19 \%$ dos jovens. Destes, $13,51 \%$ disseram que a escola não tem grêmio estudantil organizado, e $77,30 \%$ dos jovens afirmaram não ter interesse em participar de tal agremiação. Esse é um aspecto interessante a observar, pois o fato de os jovens não participarem do grêmio sinaliza que eles podem estar buscando outras formas de participação coletiva.

Quando perguntados se gostavam de frequentar a escola, 78,11\% afirmaram que sim; $15,14 \%$ disseram que gostavam às vezes; $4,32 \%$ responderam que nem sempre; e apenas 2,43\% afirmaram não gostar. Em relação aos motivos que os levam a estudar, as respostas mais significativas foram três. A pri- 
Entre o "gostar" de estar na escola e a invisibilidade juvenil: um estudo sobre jovens estudantes de Santa Maria, RS

meira refere-se ao desejo de terminar o Ensino Médio e fazer Vestibular, com um índice de $41,35 \%$ respostas nesse sentido. Um significativo número de jovens, $28,92 \%$, colocou o conhecimento acima de qualquer outro motivo para estarem na escola. Houve, ainda, uma parcela de jovens entrevistados $(15,14 \%)$ que respondeu que se encontram no Ensino Médio porque desejam, com isso, uma possibilidade de conseguir trabalho.

Quando os jovens foram perguntados sobre o que pretenderiam fazer ao concluir o Ensino Médio, 54,47\% afirmaram que pretendem fazer Vestibular; $13,82 \%$ desejam buscar um curso técnico; $5,42 \%$ optaram pelas duas possibilidades; e 7,32\% disseram que ainda não sabem o que vão fazer.

Até aqui, apresentamos alguns dados quantitativos de jovens de Santa Maria matriculados na escola pública de Ensino Médio. Cumpre-nos, agora, analisarmos duas categorias que se nos apresentaram como significativas dentre os dados esboçados e que nos permitirão aprofundar a discussão sobre a atual crise de sentido deste nível de ensino.

\section{Entre o "gostar" da escola e a invisibilidade das identidades juvenis}

\section{O "gostar" da escola}

Como já indicado, $78,11 \%$ dos jovens entrevistados afirmaram gostar de frequentar a escola e, somando-se a isso, $41,35 \%$ destacaram que isso se deve ao desejo de concluir o Ensino Médio e fazer o Vestibular. Cabe ressaltar que, do total dos entrevistados, mesmo entre aqueles que não gostam de ir à escola, $54,47 \%$ declararam que, ao concluírem essa etapa do ensino, pretendem prestar exames para o Ensino Superior, enquanto apenas $13,82 \%$ manifestaram a vontade de buscar um curso técnico.

Como diagnosticam alguns pesquisadores (COREA, 2008; DAYRELL, 2007; DI SEGNI; OBIOLS, 2006; SOUZA, 2003), dar sentido à escolarização tem sido uma tarefa difícil tanto para jovens como para professores. Os primeiros convocados diariamente a serem os protagonistas de uma cultura digital, que Ihes possibilita comunicabilidades simultâneas, contato com jogos de última geração e que assume a velocidade como marca característica de seus itinerários virtuais, ao chegarem à sala de aula, são confrontados ainda com um ambiente no qual a imobilidade e o silêncio possuem estatuto de legitimidade. Os últimos, os professores, por sua vez, veem na ausência de movimentos e interações entre pares, não raras vezes, os elementos indispensáveis para ministrarem suas aulas. Em outras palavras, perpetuam-se no cenário do Ensino Médio práticas escolares originárias de seu período fundacional, quando preparar as camadas médias da sociedade para cargos burocráticos do Estado e selecionar os filhos das classes altas para o Ensino Superior era o que dava sentido a essa etapa do ensino (ROMERO, 2007). 
Elisete M. Tomazetti - Nara V. Ramos - Sueli Salva -

Adriano M. Oliveira - Vitor Schlickmann

Apesar dessa imutabilidade do Ensino Médio, os dados destacados nos mostram uma persistente opção juvenil em prosseguir apostando na escola como um dos palcos de suas vidas, ainda que lhes pese o número de horas permanecido nessa instituição. Contudo, os mesmos números logo nos fornecem a medida dessa escolha: lançar para o futuro um sentido impossível de se construir no presente. Na ausência de um sentido para o cotidiano escolar que seja alicerçado no prazer de estar na sala de aula e de interagir com professores e saberes, lança-se para o futuro a justificativa para permanecer-se matriculado em uma instituição por demais formal $e$ alheia às novas formas de ser de jovens e adolescentes. Gostar de ir à escola, desse modo, não nos parece uma construção de sentido atrelada ao desejo de conseguir adentrar no Ensino Superior, ao final do Ensino Médio.

De outro lado, acreditamos que essa valoração se dê no âmbito do que Dayrell (2007) denominou como espaços intersticiais. São nesses entrelugares, corredores, intervalos para troca de professores, momentos de conversa na sala de aula, recreios etc., que as vivências juvenis conseguem, então, alicerçar um sentido provisório para o estar na escola. O prazer da sociabilidade, por conseguinte, sobrepõe-se ao prazer de estudar e inaugura formas de ocupar a territorialidade da instituição escolar que, não raras vezes, subvertem a sua matriz fundacional, baseada em critérios de seletividade e desempenho (ROMERO, 2007; SANTOS, 2004).

Pode-se dizer, assim, que "gostar de frequentar a escola" parece possuir múltiplos significados para os jovens entrevistados; dentre eles, significados que ignoram a própria lógica escolar, como permanecer indo às aulas para desfrutar das "zoações" e "azarações" e mesmo para simplesmente completar uma etapa do ensino, como afirmaram $41,35 \%$ dos entrevistados. Para Jerusalinsky (2004), a preocupação de todo sujeito jovem envolve o que valem e como se representam seus atos no laço social. Essa é uma imposição da qual ninguém pode se subtrair e, dessa forma, o Ensino Médio se apresenta como um palco para as múltiplas identificações que adolescentes e jovens vivenciam na busca de aceitação e reconhecimento (ALMEIDA; TRACY, 2003).

O Ensino Superior, para muitos, pode apresentar-se como uma aposta final, uma chance, mesmo que distante, dadas as desigualdades econômicas brasileiras, que colocam alguns poucos em melhores condições de alcançarem as vagas oferecidas pelas universidades públicas. No entanto, trata-se de um sentido postergado, ou seja, uma intencionalidade que não preenche o aqui e agora da sala de aula, tendo-se que, a cada momento, tentar vislumbrar uma vaga universitária que se apresenta evanescente e duvidosa para a maioria. Tudo isso parece indicar, pois, que a resposta "gosto de frequentar a escola" revela, antes que uma homogênea busca de ascensão para o Ensino Superior, diferentes modos de recriar a escola, sem abandoná-la. Frequentar a instituição, por conseguinte, de uma forma prazerosa, não significa o mesmo que "gostar da escola", de suas normas e tempos, de seus agentes e discursos. 
Entre o "gostar" de estar na escola e a invisibilidade juvenil: um estudo sobre jovens estudantes de Santa Maria, RS

Desse modo, pode-se, como sustenta Corea (2008), estar na escola sem subjetivar-se nela, lançando mão de espaços intersticiais para constituir nela outros modos de habitar o presente, mesmo que estes signifiquem a rejeição da própria cultura escolar (DAYRELL, 2007). Como os conteúdos curriculares são desprovidos de sentido para a maioria dos alunos e não possuem pertinência para a vida social diária, busca-se uma intencionalidade provisória alicerçada no futuro - como declararam $54,47 \%$ dos alunos entrevistados, ao afirmarem o desejo de realizarem exames vestibulares ao final do Ensino Médio -, futuro que, em nossa cultura competitiva e desigual, não oferece certezas e tampouco meios de deixá-lo menos incerto (BAUMAN, 1998).

Ressaltamos que a ênfase em um ensino de caráter tradicional na cidade de Santa Maria tem relação com o fato de a mesma ser uma cidade universitária, na qual os estudantes do nível médio de ensino alimentam a esperança de ingressar na universidade pública. O Programa de Ingresso ao Ensino Superior (PEIES), instituído em 1995 em caráter experimental na UFSM, define o ingresso seriado, com provas de acompanhamento realizadas ao final de cada ano do Ensino Médio. O programa deixou de ser experimental em 1997, mas permanece com a mesma sigla. O PEIES de algum modo direciona o currículo escolar a assumir fortes características propedêuticas, o que muitas vezes acaba por forjar esperanças frustradas junto aos estudantes, pois um número pouco significativo de jovens consegue ingressar no Ensino Superior através desse programa. Os jovens que ingressam no Ensino Superior público ainda são aqueles que podem, além de cursar o Ensino Médio, fazer curso pré-vestibular privado, ou seja, aqueles das classes sociais mais elevadas.

\section{A invisibilidade das identidades juvenis}

Dentre outros dados destacados até aqui, cabe-nos agora detalhar o percentual de $94,32 \%$ de jovens que afirmaram que suas escolas não oferecem outras atividades senão aquelas tradicionalmente desenvolvidas no âmbito da sala de aula. Isso significa dizer que excursões, gincanas, debates, apresentações artísticas e mesmo análise de filmes ou visitas a museus se apresentam como atividades praticamente inexistentes nas escolas pesquisadas.

Como considera Giddens (2002), o processo de construção das identidades no cenário contemporâneo requer uma tarefa constante, reflexiva e orientada para a elaboração de narrativas em múltiplos âmbitos da vida do sujeito. Desse modo, possibilidades de manifestar e defender pontos de vista, expressar gostos artísticos, mostrar-se afeito a determinados estilos cinematográficos e mesmo expressar a identificação com grupos em competições são formas de constituir histórias particulares que operam modos de conformação das identidades individuais. A escola de Ensino Médio, no entanto, como indicam alguns pesquisadores (COREA, 2008; DI SEGNI; OBIOLS, 2006; KAPLAN, 2005; CAMACHO, 2004; SOUZA, 2003), prossegue inviabilizando dispositivos que auxiliem esse processo inerente à constituição dos sujeitos jovens. Pode-se 
Elisete M. Tomazetti - Nara V. Ramos - Sueli Salva -

Adriano M. Oliveira - Vitor Schlickmann

dizer, pois, que a ausência da oferta de recursos que permitam subjetivações fora do âmbito da sala de aula e mesmo da instituição escolar opera no sentido de não legitimar outras construções identitárias senão aquela tradicionalmente outorgada de aluno - a qual, por sua vez, não permite traços de singularidade e ignora a diferença, como se a cultura juvenil engendrada fora dos muros da escola pudesse ser inviabilizada pela indiferença docente.

Apesar de tal impossibilidade, não se pode subestimar os danos subjetivos dessa tentativa de tornar invisíveis as identidades juvenis, já que a demarcação identitária nas redes sociais de convivência se faz elemento fomentador de segurança, atributo por demais importante em um cenário socioeconômico de incertezas e instabilidades. Como afirma Kaplan (2005, p. 102), "as características especiais do tempo do neocapitalismo criaram um conflito entre caráter e experiência, a experiência de um tempo desarticulado, ameaçando a capacidade das pessoas consolidarem as suas narrativas de caráter duradouro" (trad. livre). Tais condições contemporâneas, antes de serem objetos de reflexão por parte de corpo docente e diretivo das escolas, vêm sendo sistematicamente ignoradas pelas escolas de Ensino Médio pesquisadas, como mostra o alto número de alunos que afirmam a inexistência de atividades educativas nãotradicionais no âmbito da escola.

Ao lado de um processo de destituição da escola de seu papel de agente subjetivador hegemônico perante os jovens, como sustenta Corea (2008), vê-se também a tentativa das instituições escolares de manterem seu antigo monopólio pela via da invisibilidade destinada aos jovens nos espaços e tempos escolares. Noutros termos, passaram-se as décadas, mudaram-se os sujeitos da educação, contudo os professores prosseguem buscando reaver o prestígio social perdido perante os alunos através de normatividades que não legitimam as culturas juvenis. Contudo, tal postura instituída, embora inviabilize a plena participação juvenil nas pautas da escola - na medida em que os jovens passam a desinteressar-se por um contexto que não permite práticas de escutas efetivas, que possam tomar as falas juvenis como elementos para repensar as práticas docentes -, não impede que sejam elaboradas outras formas de ação por parte desses atores, de modo que seja reconfigurada a materialidade dos lugares através de outros modos de habitá-los e narrá-los.

Outro dado que consideramos importante destacar em nossa análise consiste no percentual de $77,30 \%$ dos alunos que afirmaram não possuir nenhum interesse em participar do grêmio estudantil de sua escola. $O$ estranhamento inicial das respostas dadas pelos alunos, na medida em que esperávamos um maior desejo de participação juvenil em um espaço instituído pela escola, levou-nos a acreditar, inicialmente, em uma rejeição dos jovens por ações coletivas no âmbito educativo. As reflexões de Corea (2008), entretanto, ao destacarem a falência do dispositivo escolar como produtor de sentido junto às novas gerações, auxiliaram-nos na percepção do comportamento afirmativo dos jovens diante da situação escolar, e não de passividade e apatia. O fato de 
não desejarem participar do grêmio estudantil não significou a perda de uma valiosa oportunidade, a de ver-se ouvido por professores e gestores da escola na condição de aluno. O grêmio estudantil, que se configurou durante várias décadas como um espaço concedido pela escola para a manifestação controlada dos alunos, já não é coroado de sentido por eles.

Dessa maneira, os dispositivos escolares que operavam um processo de subjetivação dos educandos já não produzem seus esperados efeitos: silenciamento durante as aulas, ausência de comportamentos que atrapalhem o professor, passividade diante dos agentes escolares, concentração direcionada exclusivamente aos saberes ministrados, as verbalizações formais, entre outros. De outro modo, predominam no cenário da escola contemporânea as conversações incessantes entre os pares, mesmo durante as aulas, brincadeiras e "zoações", não raras vezes, para com o próprio professor, discussões verbais em outros momentos e uma série de comportamentos que terminam por solapar qualquer pretensão docente de disciplinamento dos jovens na escola.

Neste sentido, podemos pensar que o grêmio estudantil, amplamente rejeitado pelos estudantes pesquisados, apresenta-se como um lugar esvaziado de sentido. Instituído pela escola, através de mecanismos de enunciação que somente demarcam lugares, não consegue preencher sua territorialidade com significações condizentes com os sujeitos que podem habitá-lo. Dito de outro modo, pode-se inferir que a normatização escolar como dispositivo para a subjetivação dos sujeitos já não se produz como em décadas anteriores, quando as instituições eram suficientemente sólidas para determinar modos de ser. $\mathrm{Na}$ falência de discursos homogeneizadores, os quais veem na condição juvenil apenas uma palavra, os jovens optam deliberadamente pela rejeição dos dispositivos escolares que se lhes oferecem, salvo aqueles em que as ações em questão sejam negociadas através de um diálogo prévio.

No caso dos grêmios estudantis, pensamos que impera, então, uma firme convicção por parte dos estudantes de que fazer parte dele não redundará em movimentos e ações na escola, mas, ao invés disso, apenas em estar em um lugar predeterminado, vago, desencaixado da dinâmica das decisões escolares e, por isso, condenado à invisibilidade desde o primeiro momento. Denotase, portanto, um arrefecimento do poder de enunciar dos professores, de seu antigo papel de orientadores de gerações mais novas, antes assegurado pelas famílias dos alunos.

Na falência dos discursos, agora destituídos das ancoragens sólidas do passado, as palavras perdem seu poder de construir sentidos, dado que as novas gerações não mais atribuem autoridade a quaisquer homens ou mulheres que não a construam através de diálogos horizontais, sem antigos formalismos (DI SEGNI; OBIOLS, 2006). Isso tem feito com que muitos gestores e professores vejam em tal contexto um sinal de problema com sua "clientela" (JARDIM, 2007), enquanto, com mais acerto, poderiam detectar que a crise do Ensino 
Elisete M. Tomazetti - Nara V. Ramos - Sueli Salva -

Adriano M. Oliveira - Vitor Schlickmann

Médio se deve à imutabilidade das práticas de uma instituição que ignora as identidades e percursos sociais dos sujeitos jovens a quem pretende ensinar (DAYRELL, 2007; CASTRO; CORREA, 2005; CAMACHO, 2004; SOUZA, 2003; FANFANI, 2000). Em uma instituição ainda configurada nesses moldes, podese afirmar com Corea $(2008$, p. 60 ) que a palavra já não formula sentidos, significados, mas somente ruídos e insensatez.

Prosseguindo nossa análise, inferimos que a não-participação dos jovens no grêmio estudantil pode sinalizar que os mesmos estão buscando outras formas de participação coletiva. A pesquisa "Juventude Brasileira e Democracia: participação, esferas e políticas públicas”, realizada pelo IBASE (2005), indica que a ação coletiva dos jovens "encontra-se orientada majoritariamente para objetivos de ordem prática em torno de valores que ganham coerência no curso e na vida cotidiana" (CARRANO, 2006, p. 5). Em relação à organização estudantil - caminho de participação mais direcionado à posição política -, por um lado, os jovens consideram-no o mais eficiente, mas, por outro, também o veem como o caminho mais sujeito à burocracia e corrupção. Os jovens também sinalizam que esse caminho é o mais suscetível à manipulação por parte dos mais velhos sobre os mais jovens (RIBEIRO et al., 2005). Castro e Correa (2005), nesta mesma linha, argumentam que a juventude tende a rejeitar as tentativas de sistematizar ações em cujo planejamento e decisões os jovens não tenham tido envolvimento.

\section{Considerações finais}

Ao deixar de cumprir com as funções de socialização que historicamente lhes foram delegadas, o ambiente escolar deixa patente, de um lado, a perda da autoridade do professor como legítimo representante da cultura produzida e responsável pela sua transmissão às gerações mais novas, e, de outro, as dificuldades da escola para efetivar a formação de mão de obra qualificada para o mercado de trabalho. Como consequência imediata, ao aluno cabe criar estratégias de permanência na escola, com o objetivo de conseguir seu certificado.

Para Matos (2008), as instituições de Ensino Médio enfrentam uma dupla crise: a político-institucional e a cognitiva dos saberes. A primeira é expressa pela indefinição identitária do que seja o nível médio de escolarização, pois esse, "à medida que vem ganhando projeção social e ampliando a sua base de influência, nessa mesma medida reforça o sentido das clivagens que o atravessam", seja pelo simples cumprimento da ampliação da escolaridade obrigatória, seja pelo prosseguimento dos estudos no nível superior, e, ainda, enquanto dinâmica mínima duma profissionalização escolarmente estruturada. Já a crise cognitiva dos saberes caracteriza-se pela colocação em pauta de "opções estratégicas do ponto de vista curricular e do enfoque das aprendizagens", promovendo um deslocamento "da questão dos saberes no plano do objeto a ensinar, supostamente sustentado em propriedades estáveis e duradouras, para o plano do sujeito que aprende" (MATOS, 2008, p. 17-20). 
Entre o "gostar" de estar na escola e a invisibilidade juvenil: um estudo sobre jovens estudantes de Santa Maria, RS

O cotidiano escolar apresenta-se como um espaço múltiplo, mas que precisa abarcar a diversidade, pois os jovens são expressão do desenvolvimento de identidades múltiplas, cambiantes, ambíguas e, até certo ponto, efêmeras (MELUCCI, 2004). Além disso, assiste-se ao dilaceramento do mito da escola como a promotora de mobilidade social e, a partir daí, questiona-se: como construir um novo sentido para essa instituição? Percebe-se, hoje, que há uma tendência a valorizar as múltiplas identidades, mas como a escola pode efetivar isso se ainda organiza-se estruturalmente para atender a grupos de trinta ou mais jovens em uma mesma sala de aula? Cada vez mais, percebe-se que a fenda entre o universo escolar e o juvenil torna-se mais ampla. A escola demonstra dificuldades em promover o diálogo com os jovens, visto que suas antigas referências significativas, antes capazes de capturar o interesse dos jovens, já não atendem às especificidades do mundo juvenil.

Enquanto os jovens absorvem de forma bastante intensa as transformações do mundo contemporâneo, a escola se mantém fiel e fixa à estrutura na qual foi criada, principalmente no aspecto elitista. Contudo, atualmente, não é apenas o jovem das classes alta e média que tem acesso à escola. Essa é frequentada por jovens provenientes dos mais diversos grupos sociais, e cada um desses grupos é signatário de culturas e identidades próprias. Essa democratização - para alguns, massificação - ocorre num momento de grandes transformações, inclusive no plano familiar e íntimo. Aliás, nem a família nem tampouco a escola mantêm-se como as principais instituições de reprodução e regulação da vida dos mais novos; o poder de ambas se dilui, relativiza-se e divide-se com outras instâncias sociais.

Afora a constatação do desinteresse e desmotivação dos jovens em permanecer nos bancos escolares, tem-se instituído, no nível médio de ensino, a "cultura do desempenho", seja na dimensão individual, expressa pelos índices a serem atingidos nas disciplinas, seja na dimensão coletiva, nas estatísticas obtidas pelas escolas nos processos seletivos de ingresso ao Ensino Superior. Em determinadas localidades e regiões, como é o caso de Santa Maria, o Ensino Médio é estruturado em currículos cujo objetivo único é a preparação para o Ensino Superior, desconsiderando, inclusive, que a maioria dos jovens ou não se coloca esse objetivo de vida, ou não tem o acesso à universidade no seu horizonte de expectativa - basta lembrar a discrepância entre os números de matrículas nesses dois níveis de escolarização. Dentro dessa lógica, cada vez mais, a escola distancia-se de um projeto próprio que considere seu públicoalvo, composto por sujeitos sociais dotados de manifestações culturais específicas, anseios e perspectivas. Ao contrário disso, mantem uma atmosfera na qual "os alunos sentem que qualquer coisa que aconteça fora do mundo escolar é mais interessante e responde mais efetivamente à etapa que estão vivendo" (DAYRELL, 2003, p. 176).

Trata-se, então, de investigar as relações que são estabelecidas entre a cultura escolar, a cultura científica e as culturas juvenis no espaço e cotidiano 
Elisete M. Tomazetti - Nara V. Ramos - Sueli Salva -

Adriano M. Oliveira - Vitor Schlickmann

da escola de Ensino Médio, assim como as percepções dos jovens sobre a escola. Para tanto, exigem-se estudos sobre essas culturas juvenis, bem como o reconhecimento de que os jovens são portadores de uma cultura social feita de conhecimentos, valores, atitudes, predisposições, que não coincidem necessariamente com a cultura escolar e, em particular, com o currículo do programa que a instituição se propõe a desenvolver (FANFANI, 2000, p. 8). De outro lado, cabe aos professores e envolvidos com a instituição escolar reconhecer que a cultura social contemporânea tem se caracterizado pela diversificação, pela fragmentação, pelo consumismo, o que tem produzido subjetividades juvenis que passam a resistir à escolarização e que são, cada vez mais, incapazes de reconhecer o valor desta, percebendo-a como obsoleta e distanciada do mundo da vida.

Para legitimar essas subjetividades, não basta abrir "lugares juvenis" instituídos - como os grêmios estudantis - sem que se tome como referência o diálogo com os estudantes e suas formas de pensar a escola. A manutenção de relações hierárquicas dificulta a construção do consenso e a prática do diálogo. Em que pesem as consequências funestas de tal situação, assiste-se, ainda, à incapacidade dos agentes da instituição escolar em reconhecer seus erros, em instituir significados para a vida social e produzir práticas pedagógicas em consonância com as transformações sociais em que nos encontramos todos inseridos.

\section{Referências}

ALMEIDA, M. I. M.; TRACY, K. M. de A. Noites nômades: espaço e subjetividade nas culturas jovens contemporâneas. Rio de Janeiro: Rocco, 2003.

BAUMAN, Zygmunt. A arte da vida. Rio de Janeiro: Jorge Zahar, 2009.

. O mal-estar da pós-modernidade. Rio de Janeiro: Jorge Zahar, 1998.

BOURDIEU, P.; PASSERON, J. C. A Reprodução: elementos para uma teoria do sistema de ensino. 3. ed. Rio de Janeiro: Francisco Alves, 1992.

CAMACHO, L. M. Y. A invisibilidade da juventude na vida escolar. Perspectiva, Florianópolis, v. 22, n. 2, p. 325-343, jul./dez, 2004.

CARRANO, P. Juventude e Participação no Brasil: interdições e possibilidades. Democracia viva: Juventude. Rio de Janeiro: IBASE, 2006.

CASTRO, L. R.; CORREA, J. Juventude Contemporânea: perspectivas nacionais e internacionais. Rio de Janeiro: Nau Editora, 2005.

COREA, C. Pedagogia y comunicación em la era de aburrimiento. In: COREA, C.; LEWKOWICZ, I. (Orgs.). Pedagogia del aburrido: escuelas destituídas, famílias perplejas. $1^{\text {a }}$ ed. $4^{\text {a }}$ reimp. Buenos Aires: Paidós, 2008.

CORTI, A. P.; SOUZA, R. Diálogos com o mundo juvenil: subsídios para educadores. São Paulo: Ação Educativa, 2004. 
Entre o "gostar" de estar na escola e a invisibilidade juvenil: um estudo sobre jovens estudantes de Santa Maria, RS

COSTA, J. F. O vestígio e a aura: corpo e consumismo na moral do espetáculo. Rio de Janeiro: Garamond, 2005, 244p.

CRIADO, E. M. De la reprodución al campo escolar. In: (Org.). Pierre Bourdieu: las herramientas del sociólogo. Madrid: Fundamentos, 2004. p. 67112.

DAYRELL, J. A escola "faz" as juventudes? Reflexões em torno da socialização juvenil. Educação e Sociedade, Campinas, v. 28, n.100 - Especial, p. 11051128, 2007.

Escola e Culturas Juvenis. In: FREITAS, M. V.; PAPA, F. (Org.). Políticas públicas: juventude em pauta. São Paulo: Cortez, 2003. p. 173-189. [Ação Educativa Assessoria, Pesquisa e Informação: Fundação Friedrich Ebert.]

DI SEGNI, S.; OBIOLS, G. Adolescência, posmodernidad y escuela: la crisis de la enseñanza media. Buenos Aires: Centro de Publicaciones Educativas y Material Didáctico, 2006.

FANFANI, E. T. Culturas jovens e cultura escolar. [mimeo]. Texto apresentado no seminário "Escola Jovem: um novo olhar sobre o Ensino Médio", organizado pelo Ministério da Educação. Secretaria de Educação Média e Tecnológica. Coordenação Geral de Ensino Médio. Brasília, 7 a 9 de junho de 2000.

GIDDENS, A. Modernidade e identidade. Tradução de Plínio Dentzien. Rio de Janeiro: Jorge Zahar Editor, 2002.

INSTITUTO BRASILEIRO DE GEOGRAFIAE ESTATÍSTICA. Censo demográfico 2000. Disponível em: http://www.ibge.com.br/censo/. Acesso em: 4 fev. 2010.

JARDIM, J. Pro dia nascer feliz. Documentário, Rio de Janeiro, Copacabana Filmes, 88 min, 2007.

JERUSALINSKY, A. N. Adolescência e contemporaneidade. In: Conselho regional de Psicologia, $7^{\text {a }}$ Região. Conversando sobre adolescência e contemporaneidade. $1^{\mathrm{a}}$ ed., Porto Alegre, Libretos, 144p, 2004.

KAPLAN, C. Subjetividad y educación. In: KRICHESKY, M. (Org.). Adolescentes y inclusión educativa: un derecho en cuestión. Buenos Aires: Centro de Publicaciones Educativas y Material Didáctico: Fundación SES, 2005.

LEITE, Elenice Moreira. Juventude e trabalho: criando chances, construindo cidadania. In: FREITAS, M. V.; PAPA, F. de C. (Org.). Políticas Públicas: juventude em pauta. São Paulo: Cortez: Ação educativa Assessoria, Pesquisa e Informação: Fundação Friedrich Ebert, 2003. P. 153-172.

MATOS, M. Jovens, alunos, ensino secundário. Revista do centro de investigação e intervenção educativa: Jovens, percursos e transições em instituições e comunidades educativas, n. 27, Universidade do Porto. Porto: Afrontamentos, 2008. 
Elisete M. Tomazetti - Nara V. Ramos - Sueli Salva -

Adriano M. Oliveira - Vitor Schlickmann

MELUCCI, A. O jogo do eu: a mudança de si em uma sociedade global. Tradução. Editora UNISINOS. São Leopoldo, 2004.

PEREZ, L. M. A experiência chilena. In: FREITAS, M. V.; PAPA, F. (Org.). Políticas públicas: Juventude em Pauta. São Paulo: Cortez, 2003. p. 173-179. [Ação Educativa: Fundação Friedrich Ebert]

RIBEIRO, E.; LÂNES, P.; CARRANO, P. Juventude brasileira e democracia: Participação, esferas e políticas públicas. Relatório final da pesquisa Juventude brasileira e democracia: Participação, esferas e políticas públicas. Rio de Janeiro: IBASE, 2005.

ROMERO, C. La escuela media en la sociedad del conocimiento. Buenos Aires: Noveduc, 2007.

SANTOS, L. de C. P. Formação de Professores na cultura do desempenho. Educação e sociedade. Campinas, v. 25, n. 89, set./dez. 2004, p. 1145-1157.

SOUZA, R. M. de. Escola e juventude: o aprender a aprender. São Paulo: EDUC/PAULUS, 2003.

SPOSITO, M. P. Algumas reflexões e muitas indagações sobre as relações entre juventude e escola no Brasil. In: ABRAMO, H. W.; BRANCO, P. P. M. Retratos da juventude brasileira. São Paulo: Fundação Perseu Abramo, 2005. p. $87-127$.

\section{Notas}

1 "Las especiales características del tiempo en el neocapitalismo han creado un conflicto entre carácter y experiencia, la experiencia de un tiempo desarticulado que amenaza la capacidad de la gente de consolidar su carácter en narraciones duraderas".

\section{Correspondência}

Elisete Medianeira Tomazetti - Av. Roraima, 1000, Cidade Universitária, 97105-900, Santa Maria, Rio Grande do Sul, Brasil.

E-mail: elisetem2@gmail.com 